
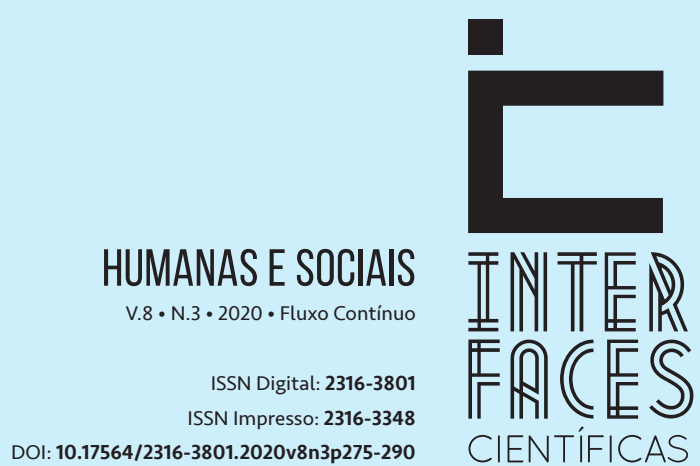

CIENTÍFICAS

\section{PROPOSTA DE FLUXO DE PROCEDIMENTOS PARA O DEPARTAMENTO DE CAFÉ DE UMA COOPERATIVA SUL MINEIRA}

PROPOSED FLOW OF PROCEDURES FOR THE COFFEE DEPARTMENT OF A SOUTH OF MINAS GERAIS COOPERATIVE

PROPUESTA DE FLUJO DE PROCEDIMIENTOS PARA EL DEPARTAMENTO DE CAFÉ DE UNA COOPERATIVA DEL SUR DE MINAS GERAIS
Sheldon William Silva ${ }^{1}$ Sidney Verginio da Silva ${ }^{2}$ Fabricio Pelloso Piurcosky ${ }^{3}$ Antonio Carlos dos Santos ${ }^{4}$ Pedro dos Santos Portugal Júnior ${ }^{5}$

\section{RESUMO}

0 artigo tem como objetivo analisar o processo de venda de café em uma cooperativa agropecuária do sul do Estado de Minas Gerais e propor um fluxo de procedimentos para essa operação. Para alcançar esse propósito, foi realizado, por meio de um estudo de caso, um acompanhamento do processo que envolve o Departamento de Café da cooperativa, desde a emissão da nota de transferência até a venda do café do cooperado. Percebeu-se com os resultados que o procedimento realizado demonstrava falhas em processos de comunicação entre matriz, filiais e cooperados, ainda, falhas operacionais nos sistemas de informações gerenciais. Outrossim, destaca-se o funcionamento do sistema de classificação do café e os procedimentos adotados. Desse modo, foi proposto um fluxo de procedimentos para o Departamento de Café que visa minimizar as faIhas de comunicação organizacional e conciliação de sistemas gerenciais e garantir eficiência operacional para a cooperativa.

\section{PALAVRAS-CHAVE}

Cooperativa. Procedimentos. Café. Comunicação. Sistemas Gerenciais. 


\section{ABSTRACT}

This paper analyze the coffee sales process in an agricultural cooperative in the southern state of Minas Gerais and propose a flow of procedures for this operation. To achieve this purpose, a case study was carried out to monitor the process involving the Coffee Department of the cooperative, from the issuance of the transfer note to the sale of the cooperative's coffee. The results show that the procedure performed showed failures in communication processes between matrix, subsidiaries and cooperatives, as well as operational failures in management information systems. Also, the functioning of the coffee classification system and the adopted procedures are highlighted. Thus, a flow of procedures was proposed for the Coffee Department to minimize the organizational communication failures and the conciliation of management systems and to guarantee operational efficiency for the cooperative.

\section{KEYWORDS}

Cooperative. Procedures. Coffee. Communication. Management Systems.

\section{RESUMEN}

El artículo tiene como objetivo analizar el proceso de venta de café en una cooperativa agropecuaria del sur del Estado de Minas Gerais y proponer un flujo de procedimientos para esa operación. Para alcanzar ese propósito, se realizó, por medio de un estudio de caso, un seguimiento del proceso que involucra al Departamento de Café de la cooperativa, desde la emisión de la nota de transferencia hasta la venta del café del cooperado. Se percibió con los resultados que el procedimiento realizado demostraba fallas en procesos de comunicación entre matriz, filiales y cooperados y, además, fallas operativas en los sistemas de informaciones gerenciales. Además, se destaca el funcionamiento del sistema de clasificación del café y los procedimientos adoptados. De este modo, se propuso un flujo de procedimientos para el Departamento de Café que pretende minimizar las fallas de comunicación organizacional y conciliación de sistemas gerenciales y garantizar eficiencia operacional para la cooperativa.

\section{PALABRAS CLAVE}

Cooperativa. Procedimientos. Café. Comunicación. Sistemas Gerenciales. 


\section{INTRODUÇ̃̃̃O}

A complexidade das relações comerciais no ambiente econômico exige das organizações formas de gestão flexíveis, que se adaptem ao mercado e busquem maximizar a eficiência operacional de seus processos internos e externos. As organizações cooperativas, tradicionalmente amparadas nos preceitos de Robert Owen (1973), que propunha a substituição de uma sociedade individualista por uma outra sociedade fundada sobre os pilares da associação e cooperação mútua, viu-se obrigada a adotar estratégias empresariais com vistas a tornar-se competitiva o suficiente para se manter no sistema de mercado capitalista. Ressalta-se também a importância econômica local de uma cooperativa, principalmente no que tange a associação e organização do trabalho produtivo de pequenos produtores.

Maior produtor e exportador de café e segundo maior consumidor do produto no mundo, o produto, no Brasil, figura entre os dez principais setores exportadores, estando na $5^{a}$ posição. Segundo o Balanço Comercial do Agronegócio, em dezembro de 2016, o produto representou 9,8\% das exportações brasileiras, movimentando o montante de US\$ 600,74 milhões. Minas Gerais figura como o estado que mais produz café no Brasil, representando mais de $58 \%$ da produção do país, com 30,72 milhões de sacas, de acordo com dados do Ministério da Agricultura, Pecuária e Abastecimento (MAPA).

Nesse sentido, é relevante compreender os procedimentos que as cooperativas estabelecem quando decidem ir ao mercado oferecer e adquirir produtos e serviços. Desse modo, pretende-se analisar o processo de venda de café em uma cooperativa agropecuária do sul do Estado de Minas Gerais, que possui cerca de 7.000 associados e recebe cerca de 700.000 sacas de café por ano. Nesse sentido, o diagnóstico da situação visa a proposição de um fluxo de procedimentos para essa operação, vinculado ao Departamento de Café da cooperativa pesquisada.

A pesquisa é um estudo de caso e privilegiou a abordagem qualitativa, utilizando-se fontes secundárias com análise documental e entrevistas semiestruturadas com os responsáveis pelas operações no Departamento de Café. Destaca-se também o papel dos pesquisadores quanto à observação dos fenômenos para compreensão da complexidade do ambiente de estudo.

A seguir, apresenta-se um panorama sucinto do cooperativismo no Brasil e os contextos e características da gestão de processos em cooperativas. Adiante, menciona-se a metodologia de pesquisa utilizada, bem como a análise e discussão dos resultados. Para finalizar, seguem as considerações finais da pesquisa, bem como suas limitações e sugestões para futuros estudos e, as referências bibliográficas consultadas.

\section{REFERENCIAL TEÓRICO}

Pinheiro e Júnior (2015) destacam que o movimento cooperativista surgiu na Europa, no século XIX, liderado por parte da classe operária, o qual se opunha às condições precárias de trabalho instituídas nas fábricas e aos baixos salários. Segundo Rios (2017), o cooperativismo como fruto do movimento operário resultou na criação de um modelo de associação com as seguintes carac- 
terísticas: (i) trata-se de uma associação de pessoas e não de capital; (ii) poder de decisão último é competência da assembleia dos associados; (iii) a repartição cooperativa da distribuição das sobras financeiras do exercício.

De acordo com Hartung (1996), o conceito de cooperativa está relacionado a um conjunto de pessoas que se organizam em forma de associação, com interesses em comuns, de participação livre e democrática, com igualdade de direitos para exercer atividades ou serviços por elas definidos. A Lei 5.764, de 16 de dezembro de 1971, rege o cooperativismo no Brasil, considerando uma cooperativa como uma "sociedade de pessoas com formas e natureza jurídica própria, não sujeitas à falência, organizadas para prestar serviços aos associados, e sem finalidade lucrativa própria".

No Brasil, o avanço do cooperativismo vem ganhando reconhecimento, uma vez que tem contribuído para o desenvolvimento social e econômico do país. Em nível nacional, as cooperativas são representadas pela Organização das Cooperativas Brasileiras (OCB) e pelas Organizações Estaduais (OCE) nas unidades da federação (PORTO; FERREIRA, 2015). Ninaut e Matos (2008) consideram que um cenário otimista está sendo estruturado, com destaque para as cooperativas ligadas ao agronegócio, principalmente os grãos.

De acordo com relatório do Serviço Nacional de Aprendizagem do Cooperativismo (SESCOOP) e do Sistema OCB, publicado em 2017, o Brasil possui hoje mais de 6,6 mil cooperativas, distribuídas em 13 ramos de atividades. Nos últimos anos, o número de cooperados alcançou o patamar de 13,2 milhões de associados e as cooperativas brasileiras geraram cerca de 376 mil empregos formais, conforme pode ser visualizado na Figura 1:

Figura 1 - Panorama do Cooperativismo no Brasil

\begin{tabular}{|c|c|c|c|}
\hline RAMO & COOPERATIVAS & ASSOCIADOS & EMPREGADOS \\
\hline Agropecuário & 1.555 & 1.016 .606 & 188.777 \\
\hline Consumo & 147 & 2.990 .020 & 14.056 \\
\hline Crédito & 976 & 7.476 .308 & 50.268 \\
\hline Educacional & 279 & 50.847 & 3.966 \\
\hline Especial & 8 & 315 & 9 \\
\hline Habitacional & 293 & 114.567 & 886 \\
\hline Infraestrutura & 125 & 955.387 & 6.154 \\
\hline Mineral & 79 & 57.204 & 187 \\
\hline Produção & 257 & 12.494 & 3.458 \\
\hline Saúde & 813 & 225.191 & 96.230 \\
\hline Trabalho & 895 & 193.773 & 1.580 \\
\hline Transporte & 1.205 & 136.425 & 11.209 \\
\hline Turismo e Lazer & 23 & 1.823 & 15 \\
\hline TOTAL GERAL & 6.655 & 13.230 .960 & 376.795 \\
\hline
\end{tabular}

Fonte: OCB (2017). 
Segundo fontes do Sindicato e Organização das Cooperativas do Estado de Minas Gerais (OCEMG), o cooperativismo mineiro fechou 2016 com 768 cooperativas distribuídas em dez ramos de atividades, 1.495 .152 associados e 38.215 empregados. As cooperativas do ramo agropecuário representam $26,4 \%$ do total (OCEMG, 2017).

Teixeira e "outros autores" (2018) sustentam que o cooperativismo tem grande importância na economia, visto que, uma cooperativa oferece a ajuda necessária aos produtores, desde conhecimentos técnicos até a aquisição de maquinário para a produção rural, o que proporciona aos seus associados vários benefícios. Ainda de acordo com seus estudos, os autores afirmam que a cooperativa elimina o propósito do intermediário, pois o cooperado produz e vende por meio da cooperativa que the oferece preços acessíveis para sua valorização, isto lhe recorre a melhores preços. Sousa "e outros autores" (2017) destaca ainda que é preciso redimensionar as estratégias para harmonizar interesses, demandas e dos públicos envolvidos em todos âmbitos da cooperativa.

Zylbersztajn (1994) aponta que o crescimento das estruturas cooperativas é seguido pelo aumento da complexidade de sua gestão, típica das grandes corporações, demandando gerentes qualificados para tratar dos complexos problemas do agribusiness. Sousa "e outros autores" (2014) consideram que a comunicação é uma ferramenta estratégica para viabilizar melhorias na gestão cooperativa, o que apresenta desafios específicos quanto às técnicas utilizadas, sobretudo para evitar o surgimento de barreiras que impeçam o desenvolvimento de fluxos de informação entre os públicos envolvidos no empreendimento cooperativo.

Antonialli e Souki (2005) advertem para as deficiências do modelo de gestão das cooperativas brasileiras. A lentidão nas decisões, comunicação ineficaz, falta de competência administrativa dos dirigentes e a falta de planejamento de longo prazo tornam as cooperativas ineficientes. Os autores concordam que, para serem competitivas, as cooperativas profissionalizar sua gestão, reduzir custos, imprimir critérios de eficiência e fidelidade no relacionamento com seus associados (cooperados) e, principalmente, evitar que interesses políticos e pessoais interfiram nas decisões estratégicas e na eficácia econômica e social dessas organizações.

Jeronimo "e outros autores" (2006) destacam que as cooperativas são empresas com uma origem e uma estrutura diferenciadas das empresas de capital. No entanto, nem sempre suas estratégias de competitividade podem diferir das estratégias das empresas não cooperativas. 0 que é característico dessas organizações, no entanto, são algumas dificuldades da gestão, que podem dificultar o estabelecimento de estratégias individuais competitivas: (i) limitação de recursos, (ii) tomada de decisão, (iii) questões políticas.

Rossés “e outros autores” (2001) apontam, em pesquisa, que um dos principais problemas identificados em cooperativas está relacionado a problemas de comunicação interna (corpo diretivo e colaboradores) e comunicação externa (referente a relação entre Cooperativa e associados). Corroborando, Nascimento "e outros autores" (2017) destacam que, no caso das cooperativas, a comunicação interna e externa se confunde, pois os cooperados são parte da empresa, porém não trabalham diretamente dentro da empresa. Portanto, a empresa precisa se comunicar com o associado e com seus clientes (comunicação externa). 
Brito, Antonialli e Santos (1997), destacam que a informação passa a ser um recurso estratégico para as organizações ao gerar condições necessárias ao alcance dos objetivos, o cumprimento da missão corporativa e subsidiar elementos básicos para melhoria da competitividade. Ainda de acordo com os autores, a competência tecnológica influencia as estratégias da organização estruturando uma relação de natureza dinâmica ao agregar valor às diversas práticas organizacionais.

De acordo com Melo e Bertolini (2017), é preciso mapear os processos utilizados nas cooperativas e identificar, desenvolver e difundir melhoras na gestão, promovendo o monitoramento e a avaliação do desempenho dos processos organizacionais e implantar melhorias no seu processo, visando alcançar mais eficiência na atividade desenvolvida pelo colaborador.

\section{METODOLOGIA}

A pesquisa tem como objetivo analisar o processo de venda de café em uma cooperativa agropecuária do sul do Estado de Minas Gerais e propor um fluxo de procedimentos para essa operação. A unidade de análise é uma cooperativa agropecuária que atua em sete municípios do sul do Estado de Minas Gerais. Por questões que envolvem o sigilo da unidade observada, dar-se-a esta o nome de Cooperativa SM.

A Cooperativa SM é uma associação de produtores rurais, não filantrópica, sem fins lucrativos, com o objetivo de apoiar as atividades agropecuárias dos cooperados. Foi constituída em 1963, sendo composta por produtores de leite, café, cereais e outros. A Cooperativa possui aproximadamente 500 funcionários, distribuídos em 50 departamentos e cerca de 7.000 cooperados. Atua na venda de sua produção agrícola e de seus cooperados nos mercados locais, nacionais e internacionais, ainda, na organização e supervisão de transporte dos produtos das fontes até a usina, postos de recepção e armazéns.

Para alcançar esse propósito, foi realizado, por meio de um estudo de caso, acompanhamento do processo que envolve o Departamento de Café da cooperativa, desde a emissão da nota de transferência até a venda do café do cooperado. De acordo com Yin (2001, p. 26) o estudo de caso é escolhido "ao se examinarem acontecimentos contemporâneos, mas quando não se podem manipular comportamentos relevantes”. Segundo Gil (2002, p. 54) o estudo de caso consiste no "estudo profundo e exaustivo de um ou de poucos objetos, de maneira a permitir o seu conhecimento amplo e detalhado".

A entrevista semiestruturada foi a técnica utilizada com a finalidade de investigar o fluxo de procedimentos realizados pelo Departamento de Café. De acordo com Boni e Quaresma (2005, p. 75), as entrevistas semiestruturadas combinam "perguntas abertas e fechadas, onde o informante tem a possibilidade de discorrer sobre o tema proposto". Ainda nesse sentido, os pesquisadores utilizaram a técnica de observação para compreensão dos detalhes e cenários envolvidos nesse ambiente de pesquisa (ZANELLI, 2002). Ainda de acordo com Günther (2006), o ponto forte da observação é fornecer instrumentos para que a análise realizada permita entrevistas e percepções coerentes com a realidade visitada. 
A pesquisa pode ser considerada descritiva, levando-se em consideração o fato de que ela pretende obter e investigar os dados referentes aos processos desenvolvidos pelo Departamento de Café da Cooperativa SM (GIL, 2002). Quanto à abordagem, a pesquisa é qualitativa, que, de acordo com Shah (2006), permite o contato do pesquisador com a situação objeto e interpretação dos fenômenos pesquisados.

\section{ANÁLISE DOS RESULTADOS}

A partir deste conjunto de informações e das discussões conceituais será apresentado o processo realizado pelo Departamento de Café da Cooperativa SM, desde a emissão da nota de transferência até a venda do café do cooperado.

O cooperado retira na cooperativa uma nota de transporte, informando quantas sacas de café pretende trazer. 0 departamento de transporte emite a nota fiscal. Ao chegar à cooperativa, 0 caminhão é pesado para conferir o peso total de entrada. Na balança é conferida a nota fiscal emitida e conferida a carga. 0 caminhão é pesado cheio e vazio para averiguar o peso líquido em café. Caso haja divergência entre o peso declarado e o peso real do caminhão, o departamento emite uma nota de compensação.

O coordenador do armazém indica onde o café será depositado (local). 0 caminhão é descarregado no armazém, onde uma equipe aloca as sacas de café, retirando amostras para classificação, carimbando cada saca de acordo com o número do lote. Os lotes são definidos de acordo com as características do café ou conforme solicitado pelo cooperado. Ao descarregar no armazém, são anotados numa ficha de papel: o código do cooperado, quantidade de lotes e sacas entregues por lote. De volta à balança, o caminhão é pesado vazio e a diferença representa o peso da carga. O sistema divide o peso da carga pela quantidade de sacas informadas, definindo assim o peso de cada saca e de cada lote. Conforme Figura 2, sugere-se um fluxo de procedimentos para a entrada do café e recepção e pesagem pela Cooperativa SM. 
Figura 2 - Proposta de Procedimentos para recepção e pesagem de café pela Cooperativa

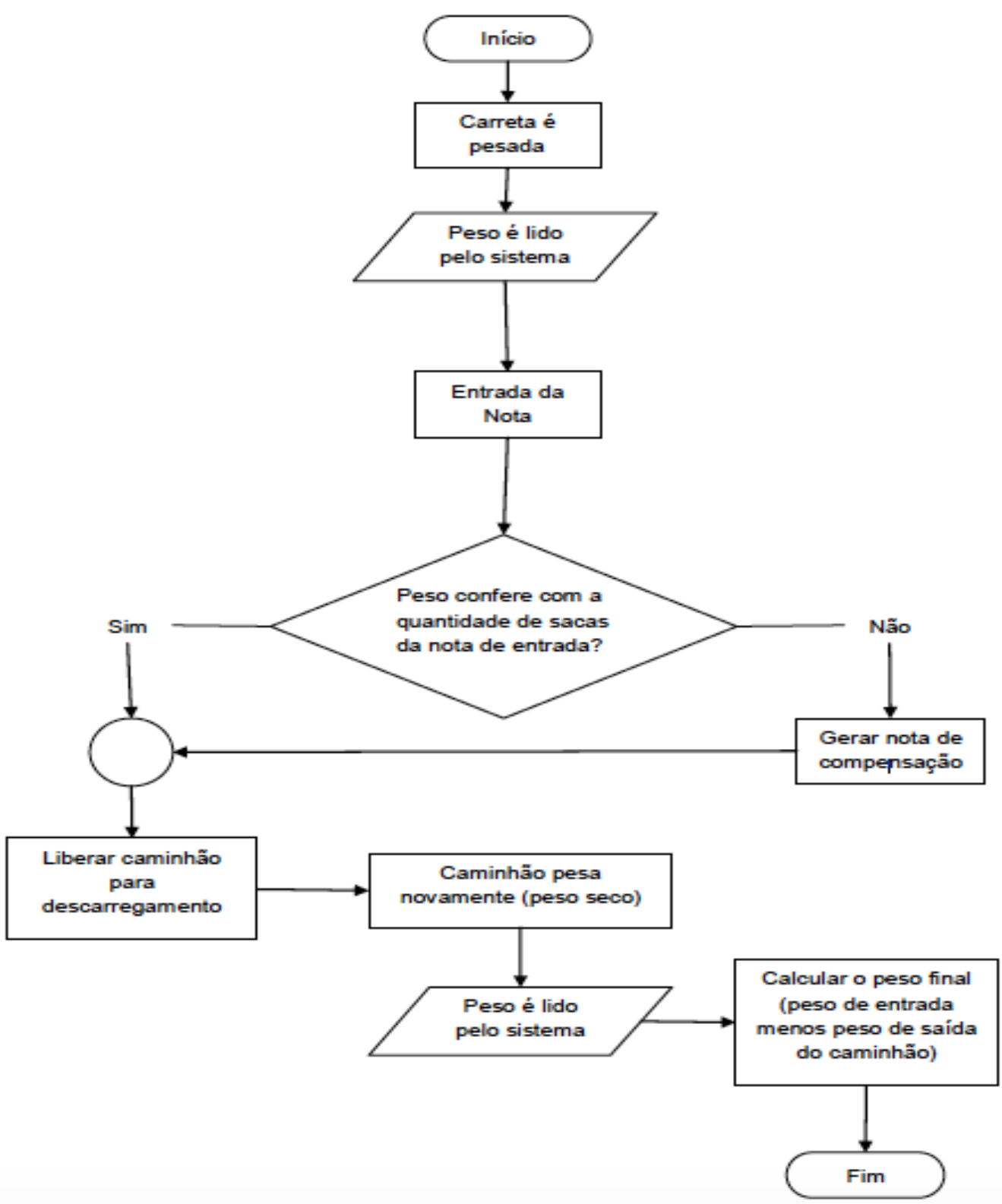

Fonte: elaborado pelos autores 
Ainda no setor de balança, os dados da ficha são lançados no sistema: código da entrada de café (número que consta na ficha), quantidade de sacas e lotes, peso, número da nota fiscal de entrada, número do armazém, número da rua e da pilha onde o café foi armazenado. As amostras também recebem esta ficha de identificação e são envidas ao setor de classificação. Ao chegar neste setor, cada amostra é analisada pelos classificadores, identificando: tipo de bebida, tipo de café, quantidade de erros, aparência da amostra, sabor etc. Estes dados são escritos em uma pequena ficha, que é passada ao supervisor do setor e lançada no sistema.

Cada lote entregue é analisado individualmente. Após este lançamento, o cooperado passa a ter uma quantidade de sacas de café de acordo com cada qualidade identificada. Pode acontecer do classificador tentar lançar no sistema a classificação do café, sem que no entanto os dados da recepção do mesmo estejam lançados. Neste caso, o sistema acusa erro (o número da nota não é encontrado) e o setor de classificação deve aguardar que o setor de balança cadastre no sistema os dados de entrada do café. Também não é possível obter informações sobre a classificação do café que estão fora de determinado padrão. 0 sistema possui regras que informam o tipo do café de acordo com a classificação do café.

Ao término deste procedimento, o cooperado tem seu saldo de café junto à cooperativa. Ele não recebe qualquer extrato da operação, a menos que solicite, no atendimento o extrato de sua conta de café. Quando o cooperado deseja efetuar venda de café, ele procura o atendimento, solicita o extrato e o verifica, informando quantas sacas de cada qualidade de café deseja vender. A atendente emite uma nota de autorização de venda, contendo a classificação do café e a quantidade de sacas que serão vendidas, que é assinada pelo cooperado. Esta nota é enviada para um encarregado que analisa os dados da venda e precifica o café.

Após precificar o café, a autorização é enviada para um atendente do Departamento de Café, que, diante do valor total da venda, verifica se o cooperado possui algum débito ou título a pagar junto a cooperativa. 0 próprio atendente realiza o pagamento de dívidas por parte do cooperado, ou seja, ocorre uma compensação entre o valor que o cooperado ganhará com a venda do café e seus títulos que deverão ser pagos.

São feitos vários descontos, como débitos em atraso e taxas para venda de café e taxa de cota capital. Os descontos são descriminados em uma nova nota emitida junto à nota fiscal. Outro ponto importante é que o funcionário deve fazer cálculos manuais para informar o preço bruto do café, uma vez que feita a precificação é informado o preço líquido. 0 sistema não está adaptado para lidar com esta entrada.

Ao final, o atendente do Departamento de Café emite uma nota de faturamento de venda do café e uma autorização de pagamento. Neste ponto, a autorização é cadastrada, informando a data da venda e data de pagamento. Novamente neste ponto pode haver entrada inválida de dados, pois as datas não são carregadas de passos anteriores. A equipe efetuou testes e conseguiu cadastrar uma autorização de pagamento com uma data anterior a emissão da nota de entrada do café. Esta autorização é enviada ao funcionário do contas a pagar, que checa a autorização de pagamento e emite o cheque para pagamento do cooperado ou efetua o depósito em conta, registrando então a baixa no pagamento. 0 fluxo de procedimentos proposto está descrito conforme Figura 3: 
Figura 3 - Fluxo de procedimentos para compensação do processo de venda de café pelo cooperado

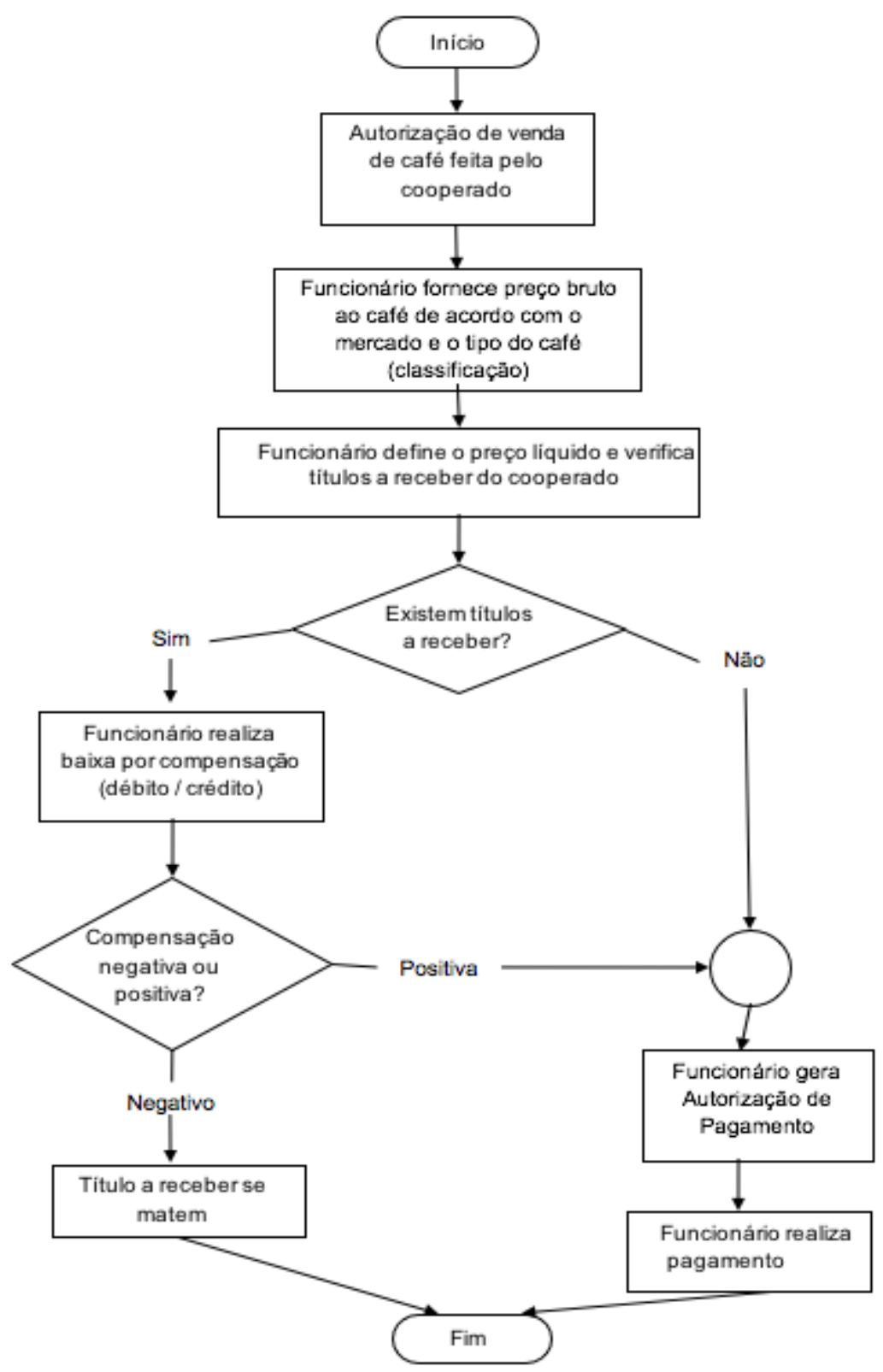

Fonte: Elaborado pelos autores. 
Conforme o relato da contabilidade, na digitação do número do cheque têm ocorrido erros. Nas filiais, nota-se que o procedimento para café é diferente do que ocorre na matriz. Os classificadores de café não possuem permissão para inserir no sistema os dados da classificação do café. É preciso que enviem ao departamento de café da matriz a ficha com os dados e aguarde o lançamento no sistema.

Segundo o classificador, ele deve consultar constantemente no sistema a situação do cooperado até que conste a classificação do café. Quando o cooperado solicita venda de café em uma filial, é preenchida uma solicitação de venda e esta ficha é passada para a matriz por fax. Somente o Departamento de café da matriz tem autorização para precificar o café. Por vezes, o cooperado espera horas para ter a resposta do preço que será pago no café, chegando a ligar a todo momento para obter a resposta.

\section{CONSIDERACÕ̃ES FINAIS}

A relação entre produtores e cooperativa se dá a partir do planejamento produtivo da empresa. Oliveira (2001) entende que estrutura organizacional contempla a delegação de tarefas, funções e responsabilidades em diferentes níveis da administração e a relação de cada parte com as demais e com a cooperativa como um todo. Nesse sentido, de acordo com o autor, a Cooperativa precisa subsidiar seus sistemas de informações gerenciais para subsidiar as decisões e estratégias organizacionais.

Percebe-se com a pesquisa realizada que o fluxo de negócios de café, embora não possua um procedimento escrito, é conhecido por todos os colaboradores do departamento. Nota-se uma dependência da matriz em relação à classificação e venda do café. Isso atrasa negócios nas filiais. Contudo, observou-se no processo de venda do café o fato de que o sistema não valida a conta corrente ao cooperado, permitindo entrada manual destes dados. Neste ponto, o sistema permite falhas de entrada de dados, pois o cooperado informa a conta corrente onde deseja receber o pagamento. Embora estes dados existam no cadastro do associado, o sistema possui um campo editável para cadastrar dados da conta corrente, o que permite informar uma conta corrente não vinculada ao usuário.

Considera-se oportuno ainda detalhar os procedimentos realizados para faturamento e conciliação de contas bancárias, tendo em vista os efeitos que podem ocasionar na finalização do processo de venda do café e o relacionamento com o associado. Na percepção dos colaboradores do Departamento de Café, o conhecimento do fluxo de procedimentos é utilizado para atender aos parâmetros internos do modelo de Gestão da Cooperativa SM, enfim, contudo, sem oferecer ao associado a clareza e conhecimento do processo. Acrescenta-se ainda a necessidade do mapeamento desses procedimentos por eventual desligamento ou demissão de colaboradores do Departamento, preservando a memória organizacional, facilitando o treinamento e desenvolvimento de novos funcionários.

É preciso também reconhecer as limitações do objeto da pesquisa. Os fluxos e procedimentos desenvolvimentos em cooperativas brasileiras não possuem singularidade, tendo em vista a necessidade de adaptação ao volume comercializado, à quantidade de associados, à área de abrangência da Cooperativa e ao mercado que atende.

A pesquisa não pretende esgotar a temática relacionada aos procedimentos e modelos de gestão em organizações cooperativas. Não obstante, espera-se que o estudo tenha contribuído para mapear, 
identificar e propor procedimentos para o Departamento de Café da Cooperativa SM. Para a academia, espera-se que a pesquisa possa fomentar futuros estudos, considerando demais parceiros da cadeia de valor como clientes, fornecedores, distribuidores e comunidade.

\section{REFERÊNCIAS}

ANTONIALLI, Luiz Marcelo; SOUKI, Gustavo Quiroga. Princípios cooperativistas e modelo de gestão: um estudo sobre conflitos de interesses entre grupos de produtores rurais. Congresso da Sociedade Brasileira de Economia e Sociologia Rural, 2005. Anais [...], Ribeirão Preto, 2005.

BRASIL, Lei. 5.764, de 16 de dezembro de 1971. Define a politica nacional de cooperativismo, institui o regime jurídico das sociedades cooperativistas, e dá outras providências. Diário Oficial da União, 16 dez. 1971.

BRITO, Mozar José de; ANTONIALLI, Luiz Marcelo; SANTOS, Antônio Carlos dos. Tecnologia da informação e processo produtivo de gestão em uma organização cooperativa: um enfoque estratégico. Revista de Administração Contemporânea, v. 1, n. 3, p. 77-95, 1997.

GIL, Antonio Carlos. Como elaborar projetos de pesquisa. 4. ed. São Paulo: Atlas, 2002.

GÜNTHER, H. Pesquisa Qualitativa Versus Pesquisa Quantitativa: Esta É a Questão? Psicologia: Teoria e Pesquisa, v. 22, n. 2, p. 201-210, mai/jun 2006.

HARTUNG, Alcyr Peters. 0 cooperativismo ao alcance de todos. Organização das Cooperativas, 1996.

JERÔNIMO, Fátima B.; MARASCHIN, A. de F.; SILVA, TN da. A gestão estratégica de sociedades cooperativas no cenário concorrencial do agronegócio brasileiro: estudo de caso em uma cooperativa agropecuária gaúcha. Teoria e Evidência Econômica, Passo Fundo, v. 14, n. 26, p. 71-90, 2006.

MAPA - Ministério da Agricultura, Pecuária e Abastecimento. Café no Brasil. 2017. Disponível em: http:// www.agricultura.gov.br/assuntos/politica-agricola/cafe/cafeicultura-brasileira. Acesso em: 3 fev. 2018.

MELO, Aline Milioni; BERTOLINI, Geysler Rogis Flor. Uma revisão teórica sobre os processos de gestão das cooperativas. Revista Eletrônica Competências Digitais para Agricultura Familiar, v. 3, n. 1, p. 88-105, 2017.

NASCIMENTO, Adriana Moraes (et al.) Cooperativismo e comunicação empresarial: um estudo das práticas da Cooperativa Agrícola Sul Matogrossense. Encontro Internacional de Gestão, Desenvolvimento e Inovação (EIGEDIN),1, 2017. Anais [...], v. 1, n. 1, 2017. 
NINAUT, Evandro Scheidt; MATOS, Marcos Antonio. Panorama do cooperativismo no Brasil: censo, exportações e faturamento. Informações econômicas, São Paulo, v. 38, n. 8, p. 43-55, 2008.

OCB, Sistema. Agenda institucional do cooperativismo. Brasília, 2017.

OCEMG, Sindicato. Anuário de informações econômicas e sociais do cooperativismo mineiro. Belo Horizonte, 2017.

OLIVEIRA, Djalma de Pinho Rebouças de. Manual de gestão das cooperativas: uma abordagem prática. São Paulo: Atlas, 2001.

OWEN, Robert. Statement Regarding The New Lanark Establishment (1812). 1973.

PERDONSINI, Dionatan et al. Pesquisa em Gestão de Cooperativas no Noroeste Gaúcho: Explorando Temas Emergentes. Salão do Conhecimento, v. 1, n. 1, 2015.

PINHEIRO, Priscila Tinelli; JÚNIOR, Humberto Ribeiro. O cooperativismo e sua importância no processo de desinvisilização social dos catadores de materiais recicláveis. Derecho y Cambio Social, v. 12, n. 40, p. 10, 2015.

PORTO, Selomi Bermeguy; FERREIRA, Marinilde Verçosa. Cooperativismo e desenvolvimento socioeconômico: uma análise da cooperativa de crédito rural de economia solidária-Solicred.

Cadernos Gestão Social, v. 5, n. 2, p. 337, 2015.

RIOS, Gilvando Sá Leitão. 0 que é cooperativismo. Brasiliense, 2017.

ROSSÉS, Gustavo Fontinelli (et al.) Sistema de Gestão em Cooperativas: o caso da Cooperativa Agropecuária Júlio de Castilhos. Revista em Agronegócio e Meio Ambiente, v. 4, n. 3, 2011.

SHAH, S. Sharing the world: the researcher and the researched. Qualitative Research, London, v. 6, n. 2, p. 207-220, 2006.

SOUSA, Diego Neves de et al. A comunicação na articulação agroindustrial entre uma cooperativa central, suas cooperativas singulares e cooperados. Revista de Economia e Sociologia Rural, v. 52, n. 3, p. 495-514, 2014.

SOUSA, Diego Neves (et al.) Entre o social e o econômico, uma gestão cooperativa é possível? Estudo sobre as estratégias de comunicação nas cooperativas agropecuárias. Revista de Extensão e Estudos Rurais, v. 6, n. 2, p. 62-80, 2017. 
TEIXEIRA, Fernanda Ribeiro (et al.) Evolução Histórica do Cooperativismo no Setor Agropecuário. Revista de Psicologia, v. 12, n. 39, p. 128-141, 2018.

YIN, Robert K. Estudo de caso: planejamento e métodos. São Paulo: Bookman, 2001.

ZANELLI, J. C. Pesquisa qualitativa em estudos da gestão de pessoas. Estudos de Psicologia, v. 7, p. 79 - 88, 2002.

ZYLBERSZTAJN, D. Organização de cooperativas: desafios e tendências. Revista de Administração, São Paulo, v. 29, n. 3, p. 23-32, jul.-set. 1994. 
1 Mestre em Administração; Doutorando em Administração pela Universidade Federal de Lavras pela Fundação Pedro Leopoldo; Professor Efetivo do Instituto Federal do Norte de Minas Gerais. E-mail: sheldon.silva@ifnmg.edu.br

2 Mestre em Administração pela Universidade Federal de Lavras; Professor do Centro Universitário do Sul Minas Gerais. E-mail: sidney@unis.edu.br

3 Mestre em Engenharia Elétrica pela Universidade Federal de São João del Rei; Doutorando em Administração pela Universidade Federal de Lavras; Professor do Centro Universitário do Sul Minas Gerais.

E-mail: fabricio@unis.edu.br

4 Doutor em Administração pela Universidade de São Paulo; Professor Titular do Departamento de Administração e Economia da Universidade Federal de Lavras.

E-mail: acsantos@.ufla.br

5 Doutor em Desenvolvimento Econômico pelo Instituto de Economia da Unicamp; Pós-doutor pelo PPPD do Instituto de Economia da Unicamp; Professor do Centro Universitário do Sul Minas Gerais. E-mail: pedro.junior@unis.edu.br

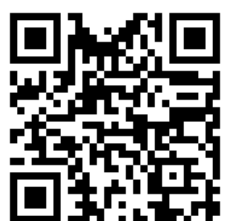

A autenticidade desse artigo pode ser conferida no site https://periodicos. set.edu.br

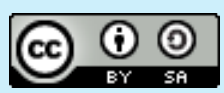

Este artigo é licenciado na modalidade acesso abertosob a Atribuição-Compartilhalgual CC BY-SA

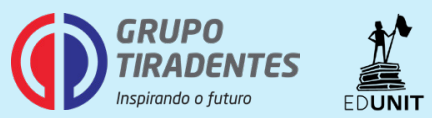


